geology". This tripartite cyclical-climatic-structural approach pervades the whole volume.

It may seem odd that so cautious and skilled a fieldworker as Machatschek should favour the one-sided Davisian idea of landform cycles, which, as R. J. Chorley shows (Frontiers in Geographical Teaching, pages 21-38, 1967), was an imaginative concept based on such discriminative components that it could not provide any single model containing a "universally appropriate approximation to a segment of reality". But the fact is that Machatschek often discards it and admits, for example, that separate parts of a landscape with the same absolute age of development may have quite different appearances and that the origin of broad transgressive surfaces, such as the Russian platform, is not to be sought in Davis's doctrine of cycles.

The volume opens with a brief survey of the general nature of the Earth's surface and of endogenous processes. This discussion carefully avoids details of the possible causes of continental drift which most British and American authors would be anxious to include and to associate them also with mountain and continentbuilding. The following ten chapters describe the various exogenous processes, with emphasis on climatic influences and dominant rock characteristics. The treatment hero is very uneven. The chapter on "Weathering : Soilformation and Soil Zones" is thin even as an introduction, whereas that on glacial landforms is much more certain. The chapters on the landforms characteristic of humid climates, including karstic outcrops, of arid climates and of coasts also have a wealth of detailed examples and astute observations.

The volume concludes with a subject index and a long bibliography that is particularly rich in German and French texts. This bibliography will be helpful only to students well versed in those languages but who presumably would hardly need the translation. More problematic is the wisdom of including in it references to nineteenth century German texts which today are only of historical interest when many internationally recognized standard texts in English are omitted. For example, there is no reference to A. Holmes, Principles of Physical Geology (1965); L. B. Leopold et al., Fluvial Processes in Geomorphology (1964); Y. F. Tuan, Pediments in Southeastern Arizona (1959); and H. J. Wiens, Atoll Environment and Ecology (1962). Equally puzzling is the inclusion of texts in German that are better done (translated, revised, etc.) or equally well covered in English. For example, what is the point of giving Davis's Die Enstehung von Korallenriffen (Z. Ges. Erdk. Berl., 1928) when his The Coral Reef Problem (1928) is readily available? Or E. Suess's Das Antlitz der Erde (1885-1909) when W. J. Sollas's translation The Face of the Earth is so outstanding?

Students, however, will be grateful for this excellent production and careful translation of the ninth edition of a book that is not particularly easy to read in the original. The retention in parentheses of German terms means that the translation will serve also as an introduction to German terminology in geomorphology.

Robert P. Beckinsale

\section{BACKDROP TO THE ASWAN}

\section{Desert and River in Nubia}

Geomorphology and Prehistoric Environments at the Aswan Reservoir. By Karl W. Butzer and Carl L. Hansen. Pp. xxi +562. (University of Wisconsin Press: Madison and London, February 1969.) \$17.50; $167 \mathrm{s.}$

'THe construction of the Aswan High Dam, which began just over ten years ago, triggered off an unparalleled series of investigations into the prehistory and cultural heritage of Nubia. After a Unesco appeal, numerous expeditions began well-publicized rescue digs and crash studies which have enabled former temples, village sites and cemeteries to be recorded and in some instances removed to sites above the rising waters of the reservoir.

With such a wealth of archacological material, it is fortunate that landforms and associated sediments have been studied also and that details of past enviromments and their position within the chronology of the Nile have also been rescued before submergenee of the vital evidence.

Desert and River in Nubia records the geomorphology and prehistoric environments of a 375 mile stretch of the Nile valley as investigated by the Yale University Prehistoric Nubia Expedition. In 457 pages, followed by a series of appendices, Butzer and Hansen succeed in applying detailed techniques to their vast area without obscuring the thread of the main story of Nile evolution.

Emphasis is on the later Pleistocene and Holocene deposits, as here the record is more easily deciphered and the archaeological data are most abundant. Thus chapters three and six deal, in a total of 135 pages, with the sedimentary sequences of the Kom Ombo Plain and Egyptian Nubia. New lithostratigraphic terms are defined and the type sections upon which the formations are based are described in detail. The processes involved during the deposition of the different units are outlined, and each section closes with a review of the stratigraphic and climatic conclusions.

These two chapters set out the principal new facts, but they are placed into a wider and historical context by chapters two and five, which deal with the geomorphic evolution of the Kom Ombo Plain and Egyptian Nubia. This is perhaps an unusual use of the term geomorphic, involving as it does an artificial separation of certain geomorphological aspects from those governing the deposition and morphology of the late Pleistoceno and Holocene sediments. Details are recorded of the solid or bedrock geology which is again artificially separated from the 'Tertiary pediplains, Pliocene and early Pleistocene sediments and features associated with the Proto-Nile.

Chapters seven and eight deal respectively with the Kurkur Oasis and the Coastal Plain of Mersa Alam. Chapter seven contains a detailed regional account of the evolution of pediments in the Kurkur area, the age and interrelations of Plateau Tufas to local cuestas, and of the complex relations between various ages of Wadis and Tufas. Climatic inferences are discussed and the sequence is related to the pattern of prehistoric occupation. The Coastal P'lain deals in similar manner with the Pleistocene littoral deposits, the stratigraphy of former sea levels during the Pleistocene and the palaeo-climatic background.

The above chapters provide a regional palaeo-environmental picture or rather a series of local palaeogeomorphologies which are consolidated in the final chapter, modestly entitled "Towards a History of the Saharan Nile". A more detailed analysis of the vectors which might be considered to have conditioned the prehistoric settlement of the Kom Ombo Plain is given in chapter four. Here an attempt is made to set the cultural information more clearly against the environmental backcloth inferred from the geomorphological-stratigraphical studies. As a contribution to an interdisciplinary programme, the volume succeeds at various levels. Not only is the evolution of the regional environment lucidly explained for the archaeologist, but in the detailed appendices, ranging through a consideration of mechanical analysis, heavy and clay minerals, isotopic ages and micro- and macroscopic palaeontology, the results of modern techniques are available for the specialist geographer or geologist.

The interplay of desert and fluviatile influences, as implied by the title, is constantly kept in view. The volume records a sories of refreshingly realistic investigations which will do much to counterbalance the effects of the inevitable but artificial pigeonholes into which these topics must be categorized at a textbook level.

W. W. Bishop 